\title{
Purchase of Consumer Behavior in the Event of Natural Disasters, Shows New Cultural Values?
}

\author{
Giulia Netti ${ }^{1}$ \\ ${ }^{1}$ Department of Economics, Lum Jean Monnet University, Casamassima (Ba), Italy \\ Correspondence: Giulia Netti, Department of Economics, Lum Jean Monnet University, Casamassima (Ba), Italy. \\ E-mail: netti@lum.it
}

Received: October 29, 2018

Accepted: November 30, 2018

Online Published: January 25, 2019

doi:10.5539/ijbm.v14n2p141

URL: https://doi.org/10.5539/ijbm.v14n2p141

\begin{abstract}
Specifically, this article is a pre-test to understand if a population considered individualistic, such as the Italian population, in the study carried out by Hofstede, in particular cases resulting from a shock, in other words from the advent of a natural disaster, highlight cultural values that were previously unidentifiable.

A statistical analysis was conducted, through the administration of a questionnaire, via the web thanks to the use of social media such as facebook and whatsapp.

The results of this pre-test that registered a number of 263 replies to the questionnaire, shows that the Italian population in the event of a natural disaster, shows a high cultural value, understood as a strong propensity to social and economic aid, identifying values collectivistic and no longer individualistic.

However, this research work has many limitations that can be overcome through a more in-depth and complete analysis.
\end{abstract}

Keywords: consumer buying behavior, organizational culture, natural disasters, shock

\section{Introduction}

This study takes into account different theories since there are no references in the literature concerning the social culture and a shock caused by the presence of natural disasters in the consumer profile.

In fact, in a time like this, in which most overwhelms the force of nature and disrupts countries and populations, it is interesting to understand how consumers of a nation stricken by a natural disaster react to it and whether such events awaken values within of their social culture.

The theoretical framework from which we start is that described by Hofstede (1990) to create a new model with the addition of the values, that is the heart of culture, the "provisional values" coming out in the moment of shock and natural disasters highlighting thus not only different and therefore different behaviour practices, but the presence of the first feelings and values forgotten as the propensity to helping your neighbour as if it were a family member.

Another aspect of the literature that will be introduced is the consumer buying behaviour and research in terms of consumer shock and the consequences of natural disasters. In order to be our starting point to open a new line of research that includes all these aspects.

We are concerned about whether understand the buying behaviours of Italian consumers in conditions of shock changes from its usual behaviour, in order to help its Italian countrymen affected by a natural disaster.

This work will be divided into a first part in which we outline the issues in question through the existing literature, on its way to the creation of our theoretical framework and our research question. While the final part will highlight the findings resulting from our statistical analysis. In conclusion we will be exposed the limitations of this research and possible future research.

\section{Theoretical Background}

\subsection{The National Culture}

According to the studies conducted by Hofstede $(1983,2010)$, which it divided according to more or less high degree identifies the first four and then six dimensions of culture, these dimensions are crucial to study and 
understand any nation and can better interact with it both in social and economic.

An example is a company that enters into a different market than national, which must in order to better relate to it, aware of its characteristics, values and behaviours of individuals.

The dimensions studied and identified by Hofstede (2010) are:

- Individualism versus Collectivism;

- $\quad$ Large or Small Power Distance;

- $\quad$ Strong or Weak Uncertainty Avoidance;

- Masculinity versus Femininity;

- $\quad$ Long-Term vs. Short-Term Orientation;

- Indulgence versus Restraint.

Hofstede (1983) argues that the Italian national culture is individualistic and therefore each person is interested in making his own interests or, at most, to worry about the small group to which it belongs, such as his family.

This work, however, takes into account only the first relative dimension to the study of Hofstede, that inherent individualism to collectivism. For the purpose of this work, it is interesting that in 2010 distinguishes two degrees of this size.

In fact, Hofstede (2010) states that the individualist populations are characterized by the presence of the ego on us, every person is considered a single and tasks prevail on relations between people, while, conversely, collectivism is the "us" of the "victory" the "I", each person is considered as belonging to a group and relationships outweigh the duties.

In this case our processed tries to verify whether the allegation made by Hofstede (2010) is always correct or within the core of the culture (Hofstede, 1990) there are values that are set aside and coming out in moments of great difficulty.

Hofstede in 1990 identifies the core of culture in the "values" and divides the practice rituals, heroes and symbols. So, highlights how the values are the foundation of culture and that these do not change over time, but rather, that are part of every person's life from birth until the age puerile, through family education and context social environment in which they live and that only later appropriated these values, behaviour and therefore implement practices that highlight the features. In addition, Hofstede says that in contrast to values which are intrinsic to the individual and therefore cannot be changed, however the behaviour may change over time, or at certain intervals of stories experienced by an individual.

However, in the literature there have been many studies on the culture and several authors have described and defined the same such as Clyde Kluckhohn (1962) and Edward T. Hall (1976).

\subsection{The Behaviour of Consumer Purchasing}

The role of consumers and therefore marketing has changed dramatically over the years.

You are moving from the purchase of traditional products, unsustainable to sustainable products. But here it does not take into account the type of product but the factors that affect consumer buying behaviour in a normal context, i.e. without the presence of shock.

But it still seems important to point out that over the past two decades consumer awareness and

The last two decades consumer awareness and the growing importance of sustainability, defined as "development that meets the needs of the present without compromising the ability of future generations to meet their own needs" (WCED Our Common Future), and issues of safety and environmental conservation have become and are becoming more and more a central pivot attitudes and consumer purchasing behaviour.

The consumer buying behaviours depend on a number of factors that are widely studied in the literature such as demographics where there are variables such as age, sex, education and income (Straughan \& Roberts, 1999 Kinnear et al, 1974).

Other authors like Mostafa (2007), identifies the consumer buying behaviour, specifically to more sustainable products through the values, knowledge, concern for the environment.

Kollmuss and Agyeman (2002) explored a range of stimuli that lead to pro-environmental behaviour, such as demographic factors such as sex and education, external factors, be they institutional, economic, social and cultural rights, internal factors such as motivation, Environmental knowledge, right, attitude, environmental awareness, emotional involvement, locus of control, responsibilities and priorities. 
Other factors that may affect consumer buying process, according to the literature are: brand strength, cultures, demographic characteristics, finance, habit, lack of information, life styles, personalities or trading off between different ethical factors. (Biel \& Dahlstrand, 2005; Sener and Hazer, 2008; Wheale and Hintom, 2007).

Ultimately, it can be said, whether it is green product than the consumer buying behaviour depends on the price of the product, the consumer culture, from its income level, from his education, from information and knowledge from brand, etc. on the characteristics of the product.

These elements there have been useful to the end of this analysis to understand which variables included in the questionnaire, in order to identify the priorities that the Italian consumer terminates brings into being during the purchase and whether and to what factors might decide to give up to achieve a higher goal, led by his "stored value", i.e. helping others, a person unknown to him but suffering from a serious environmental problem.

\subsection{The Shock and Natural Disasters in the Literature}

Many studies have been conducted on the shocks affecting consumers, however, refer not to natural disasters but rather to problems and price fluctuations (Otoo, 1999) or in reference to a shock realized through strong advertising (M Rajesh et al., 2003).

While regarding the literature on natural disasters they are not present many studies concerning the consumer and the evolution of its buying behaviour to help others. There are some studies on trends and the business issues involved in natural disasters (Sanchez et al, 1995) or studies on consumer behaviour changes but have personally suffered and experienced a natural disaster (Rajesh et al, 2003).

These events, in the case of shocks are the points of advertising and price view for example, do not refer to the values but rather to changes in behaviour of people, while in contrast, studies on the environmental disasters of people directly affected by natural disasters lead the creation of new values, the leakage of "provisional values" and a new vision of life is in the soul and in behaviour.

These few lines, inherent shocks and natural disasters by adding the study of culture of a nation and the factors affecting the buying behaviour, allow us to create a new framework that responds to our research question.

As can be seen from the figure below, our framework is based on the values and practices studied and identified by Hofstede (1990) but nevertheless locates within the heart of the culture not only the values but also the "provisional values." In our "values aside" are values that an individual possesses he does not remember to have, and that you show all their strength when a big shock arising from the event of a natural disaster occurs.

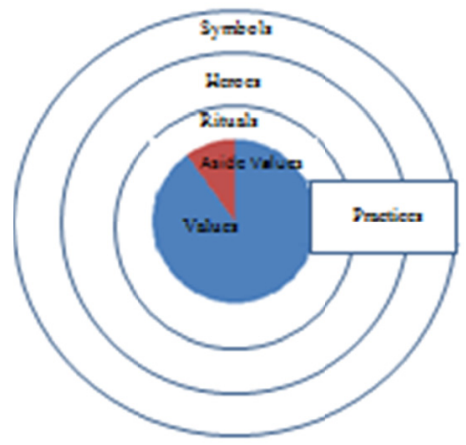

Figure 1. A new framework of culture. Reworked version of Manifestation of culture (Hofstede, 1990)

The research question that this paper seeks to answer is:

There are provisioned values, for example, consumers belonging to a nation culturally classified as individualistic, collectivist values may show instead?

\section{Research Methodology}

It was drawn up in a national language questionnaire comprising 18 questions regarding the purchase of food, divided as follows:

- The first part presents questions of general and demographic nature, in order to understand the level of education, age, profession, number of family with which he lives and income;

- The second part, however, is characterized by the presence of questions identifying their purchasing behaviour, focusing much attention to the influences acting on it as, product quality, wholesomeness, taste, 
refinement, product features the presence of information, the price, the brand, the presence in stores and packaging.

- While the last part of the questionnaire is characterized by questions about the willingness to help those affected by natural disasters, the identification of the driver of consumption to which consumers are willing to give up to help others and to ' any forbearance of a price increase, when they decide to buy food from a region affected by a natural disaster.

The questionnaire was administered via the web, specifically through social media like Facebook and Whatsapp.

Consumers who responded were 263 of these were made and statistical analysis to understand trends and to answer to our research question.

However, it is right to point out that this research work is its own pre-test to understand in broad terms if there is a chance to further this study, both in terms of a more representative sample of the Italian population and in terms of econometric analysis.

\section{The Results}

As the data, the 263 achieved responses were for $53.3 \%$ women and $46.4 \%$ men, with regard to the level of education is the highest figure is inherent in the high school diploma, while the origin of the questionnaires it is spread all over the national territory, with a larger number of responses from the Puglia region.

Among the highest incomes we find income between 1000 and 2000 euro, with a percentage of $32.3 \%$ followed by over 3000 euro. However, entering the hot zone of our analysis, we find the most important purchase driver, product quality, the taste, the information and the price.

Being asked for help to people affected by natural disasters, changing their buying behaviour, $94.3 \%$ answered it while only $5.7 \%$ said no.

Of this $94.3 \%$ there is a considerable decrease of the factors that accounted for prior to the purchase decision. In particular, the price factor passes in the second floor whereas the $75.7 \%$ of respondents is willing to pay a higher price to buy a product from a region hit by a natural disaster.

Very interesting is the data concerning the percentage of price increase taken into account, in fact, $35.7 \%$ of respondents would be willing to pay $10 \%$ more in order to help that population, which however would not be willing to pay for any other product food does not derive from regions affected by natural disasters.

Ultimately, this is undertaken as a positive response to the possibility of a presence of a "stored value" in the hearts of the Italian population, such that, in special cases such as the occurrence of a natural disaster, the Italian population goes from being a company individualist to a collectivist society. With a great willingness to help people and the economy of a region in difficulty.

\section{Limitations and Future Research}

This research is a pre-test, and also highlights many limitations. First of all, and that the analysis sample and of only 263 responses, and also that the analysis performed view short search times is only focused to a statistical analysis by not adopting an econometric analysis as the creation of a regression to better understand what factors have the most affection of other than our research question. Also, it should be taken more deeply into the part of the literature.

However, these limits are abundantly surmountable, as we considered this a pre-test and that a more detailed analysis will be carried out. There are a lot of research regarding these issues studied as a whole and, therefore, this research could be a good push to encourage studies in this regard.

\section{References}

Biel, A., Dahlstrand, U. (2005). Values and habits: a dual-process model. In Krarup, S., \&Russell, C. S. (Eds), Environment, Information and Consumer Behaviour (pp. 33-50). Elgar: Cheltenham.

Dahl, D. W., Frankenberger, K. D., \& Manchanda, R. V. (2003). Does it pay to shock? Reactions to shocking and nonshocking advertising content among university students. Journal of advertising research, 43(3), 268-280. https://doi.org/10.1017/S0021849903030332

Hofstede, G. (1983). The cultural relativity of organizational practices and theories. Journal of International Business Studies, 14(2), 75-89.

Hofstede, G. (1990). Measuring organizational cultures: A qualitative and quantitative study across twenty cases. Administrative Science Quarterly, 286-316. https://doi.org/10.2307/2393392 
Hofstede, G. (2010). The GLOBE debate: Back to relevance. Journal of International Business Studies, 41, 1339-46. https://doi.org/10.1057/jibs.2010.31

Hofstede, G. (2011). Dimensionalizing cultures: The Hofstede model in context. Online readings in psychology and culture, 2(1), 8. https://doi.org/10.9707/2307-0919.1014

Hofstede, G., Hofstede, G. J., \& Minkov, M. (2010). Cultures and Organizations: Software of the Mind (3rd ed.). New York: McGraw-Hill.

Kinnear, T. C., Taylor, J. R., \& Ahmed, S. A. (1974). Ecologically concerned consumers: who are they'? Journal of Marketing, 38, 20-24. https://doi.org/10.2307/1250192

Kollmuss, A., \& Julian, A. (2002). Mind the gap: why do people act environmentally and what are the barriers to pro - environmental behavior? Environmental education research, 8(3), 239-260. https://doi.org/10.1080/13504620220145401

Mostafa, M. M. (2007). A hierarchical analysis of the green consciousness of the Egyptian consumer. Psychology\& Marketing, 24(5), 445-473. https://doi.org/10.1002/mar.20168

Otoo, M. W.. (1999). Consumer sentiment and the stock market. FEDS Working Paper No. 99-60. http://dx.doi.org/10.2139/ssrn.205028

Sanchez, J. I., William, P. K., \& Diana, M. V. (1995). Corporate support in the after math of a natural disaster: Effects on employee strains. Academy of Management Journal, 38(2), 504-521. https://dx.doi.org/10.2307/256690

Sener, A., \& Hazer, O. (2008). Values and sustainable consumption behaviour of women: a Turkish sample. Sustainable Development, 16(5), 291-300. https://doi.org/10.1002/sd.329

Straughan, R. D., \& James, A. R. (1999). Environmental segmentation alternatives: a look at green consumer behavior in the new millennium. Journal of Consumer Marketing, 16(6), 558-575. https://doi.org/10.1108/07363769910297506

Wheale, P., \& David, H. (2007). Ethical consumers in search of markets. Business Strategy and the Environment, 16(4), 302-315. https://doi.org/10.1002/bse.484

\section{Copyrights}

Copyright for this article is retained by the author(s), with first publication rights granted to the journal.

This is an open-access article distributed under the terms and conditions of the Creative Commons Attribution license (http://creativecommons.org/licenses/by/4.0/). 